\title{
Üniversite Öğrencilerinin Mevsimsellik ve Öznel İyi Oluş Düzeyleri Arasındaki İlişkide Depresyon ve Anksiyetenin Aracı Rolü
}

\author{
Arş. Gör. Elvan KİREMİÇİ CANIÖZ* \\ Abant İzzet Baysal Üniversitesi, Fen-Edebiyat Fakültesi, Psikoloji Bölümü, Abant / Bolu / Türkiye, \\ kiremitci.elvan@gmail.com, ORCID: 0000-0003-4733-4780

\section{Prof. Dr. Hamit COŞKUN} \\ Abant İzzet Baysal Üniversitesi, Fen-Edebiyat Fakültesi, Psikoloji Bölümü, Abant / Bolu / Türkiye, \\ hamitcoskun2000@gmail.com, ORCID: 0000-0002-5509-8717
}

\section{$\ddot{O} z$}

Bu çalışmada, mevsimsellik ve öznel iyi oluş arasındaki ilişki ve bu ilişkide depresyon ve kaygının aracı rolü incelenmektedir. Mevsimsel değişimlerin kişileri psikolojik yönden oldukça etkilediği göz önünde bulundurularak, mevsimlere bağlı olarak görülen hava koşullarındaki değişimlerin olumlu ve olumsuz duygular üzerindeki etkisi araştırmacıların başlıca ilgi konusu olmaktadır. Yapılan birçok araştırma bulgusu da, mevsimsellik ve öznel iyi oluş, yani mutluluk arasında negatif yönde anlamlı ilişki bulunduğunu göstermiştir. 168 kız ve 59’u erkek olmak üzere Abant İzzet Baysal Üniversitesi'nde değiş̧ik bölümlerde okuyan 227 öğrenci bu araştırmaya katılmıştır. Bu çalışmada üniversite öğrencilerinin mevsimselliği, Rosenthal, Genhart, Sack, Sckwerer ve Wehr (1987) tarafindan geliştirilen ve Noyan, Elbi ve

* Sorumlu Yazar. Tel: +905534341024

(C) 2018 Kalem Eğitim ve Sağlık Hizmetleri Vakfı. Bütün Hakları Saklıdır. 
Korukoğlu (2000) tarafindan Türkçeye uyarlanan Mevsimlik Örüntü Ölçeği ile ölçülmüş, yaşam doyumu Diener, Emmons, Larsen ve Griffin (1985) tarafından geliştirilen Yaşamdan Memnuniyet Ölçeği ve depresyon ve anksiyete semptomları ise Derogatis (1992) tarafindan geliştirilmiş ve Şahin ve Durak (1994) tarafindan Türkçeye uyarlanmış Kısa Semptom Envanteri ile ölçülmüsstür. Araştırmacı tarafından gerçekleştirilen çalışma bulguları da alanyazın bilgisi ile tutarlılık göstermekte ve değişkenler arasındaki negatif ilişkiyi desteklemektedir. Ayrıca, çalışmada mevsimsellik ve öznel iyi oluş arasındaki ilişkide depresyon ve anksiyete puanlarının aracı rolü olduğu görülmüştür. Araştırmacı tarafından mevsimsellik ve öznel iyi oluş arasındaki ilişkinin incelendiği bu çalışmada, iki değişken arasındaki ilişkiyi inceleyen bir kuramın alanyazında yer almaması nedeniyle, bu değişkenler arasındaki ilişki Bağ Kuramı ve Duygusal Kararsızlık Kuramı çerçevesinde ele alınmıştır.

Anahtar Kelimeler: Mevsimsellik; Öznel iyi oluş; Mutluluk; Depresyon; Anksiyete.

\title{
The Mediating Role of Depression and Anxiety on
}

Relation Between Seasonality and Subjective Well-Being

\begin{abstract}
In this study, the relationship between differences in seasonality and well-being, and mediator role of depression and anxiety in this relationship were examined for the first time in the literature. Considering that seasonal changes are highly influential in the psychological states, the effects of seasonality or changes in weather conditions on positive and negative emotions are the main focus of researchers. Many research findings have also shown that there is a significant negative relationship between seasonality and subjective well-being, that is, happiness. A total of 227 students, 168 girls and 59 boys, from various departments at Abant İzzet Baysal University, participated in this study. In this study, seasonality of university students was measured by Seasonal Pattern Questionnaire (SPAQ) which was developed by Rosenthal, Genhart, Sack, Sckwerer and Wehr (1987) and adapted to Turkish by Noyan, Elbi and Korukoğlu (2000), life satisfaction was measured by the Satisfaction with Life Scale which was developed by Diener, Emmons, Larsen and Griffin (1985) and depression and anxiety symptoms were measured by Depression Scale of Brief Symptom Inventory which was developed by Derogatis (1992) and adapted to Turkish by Şahin and Durak (1994). The findings of this research are
\end{abstract}


also consistent with the findings of the literature and support a negative relationship between these variables. In addition, depression and anxiety scores were found to play full mediator role in the relationship between seasonality and subjective well-being. In this study, the relationship between these variables was considered in the context of the Association Theory and Emotional Instability Theory, because the literature did not include a theory that did reveal the relationship between these variables.

Keywords: Seasonality; Subjective well-being; Happiness; Depression; Anxiety.

\section{Extended Summary}

Seasonality and subjective well-being are one of the most interesting and popular topic in psychology research literature. Considering that changes in weather conditions such as sun, rain or snow, there is a hypothesis that the seasonal changes affects mood. For instance, people mostly feel positive feelings in spring or summer more than in autumn and winter (Reinberg and Ashkenazi, 2003). Additionally, some people have more negative feelings in autumn and winter and also tend to have much more psychological problems, such as depression, than other people (Methippara et al., 2009). In DSM-V, Seasonal Affective Disorder (DSM-V) is defined as one category, which shows itself with symptoms such as feeling negative feelings, alone mostly, not wanting to go home to outside, eating, sexual, and sleep problems. The people who have seasonal affective disorder, tend to show depression symptoms when the autumn or the winter comes. This psychological problem is named 'winter depression' (Ekinci, Okanlı and Gözüağca, 2005; Roecklein and Rohan, 2005; Rosenthal, Sack, Gillin, Goodwin, Davenport, Mueller, Newsome and Wehr, 1984. On the other hand, some people have this kind of symptoms during the spring or the summer and this psychological problem is named 'summer depression'. Given the evidence form depression studies, we see that depression symptoms can occur with the anxiety symptoms. Thus, we can say that the people, who have depression symptoms, can have anxiety symptoms too or tend to have anxiety symptoms more than other symptoms (Simrén et al., 2002).

\section{Purpose}

In this study, we examined differences in seasonality, subjective well being, depression and anxiety of university students, relationship between seasonality and subjective well-being and mediator role of depression and 
anxiety in this relationship.

\section{Method}

The population of this study consisted of university students who enrolled in Psychology, Psychological Counseling and Guidance and Mental Disabilities and Special Education Teacher at Abant Izzet Baysal University. A total of 227 students, 168 women and 59 men, participated in this study. All data were analyzed by a means of the SPSS 20.0 version In this study, seasonality of university students was measured by Seasonal Pattern Questionary (SPAQ) which was developed by Rosenthal et al. (1987) and adapted to Turkish by Noyan, Elbi and Korukoğlu (2000), subjective well-being was measured by the Subjective Well-Being Scale developed by Tuzgöl-Dost (2004) and depression and anxiety symptoms were measured by Depression Scale of Brief Symptom Inventory developed by Derogatis (1992) and adapted to Turkish by Şahin and Durak (1994).

\section{Results}

In the analysis of the data t test, one-way ANOVA, regression analysis and mediator analysis were used. The findings were evaluated at .05 significant levels. The findings of the study can be summarized as follows; there was not significant difference of gender on seasonality and depression. There were positive and high relationship among seasonality, subjective well-being, depression, and anxiety variables. Meditational analyses showed that depression and anxiety played mediator role between seasonality and subjective well-being. Even though previous studies reported a high relationship between seasonality and subjective well-being, no research has illuminated underlying mechanisms for this relationship so far.

\section{Discussion}

This study showed that this relationship was largely due to mood disorders such as depression and anxiety. Given this new evidence, it can be concluded that seasonality itself does not affect well-being. Seasonality can negatively influence well-being when person suffers from depression and anxiety. What psychologically needs to be done is to understand the relationship between seasonal changes and psychological mood disorders and prepare treatment model for eliminating link between these variables.

\section{Conclusion}

Despite new advancements in this study, one should keep in mind that 
this study is not cause-and-effect study. The future studies should manipulate seasonal changes and examine their effects on depression and anxiety. Longitudinal studies are also needed with some physiological measures such as EEG, pulse and skin conductance.

\section{Mevsimsellik ve Öznel İyi Oluş}

\section{Giriş}

\section{Mevsimsellik}

İnsanlar mevsim geçişlerine bağlı psikolojik semptomlar yaşamaktadır. Mevsime bağlı yaşantılara ve hava şartlarında görülen değişiklikler gibi çevresel faktörlerde meydana gelen değişime mevsimsel değişim, mevsimsellik adı verilmektedir (Bakım, Karaahmet, Altınbaş ve Oral, 2013). Bu değişimler rastgele değil, bir ritim içinde olmaktadır. Çoğu canlı, biyolojik ritmini dünyanın yıllık ve günlük hareketlerine bağlı olarak düzenlemekte ve ortaya çıkan bu ritme veya döngüye biyolojik ritim adı verilmektedir (Arendt, 2012; Bjorvatn ve Pallesen, 2009). Bu ritim periyot, s1klık ve evre gibi açılardan da tanımlanabilmektedir. Örneğin, periyot, bir ritmin tek bir döngüdeki zaman dilimine; sıklık (frekans), belirli bir zaman dilimindeki tekrarlama sayısına ve evre ise, bir ritmin başlangıç ve bitiş zamanları arasındaki bölüme karşılık gelmektedir (Selvi, Beşiroğlu ve Aydın, 2011). Ayrıca, biyolojik ritim, döngülerin sürelerine bağlı olarak sirkadyen ritim (24 saatlik), diurnal ritim (gün boyunca değişen döngüsel olaylar), ultradiyen ritim (24 saatten daha kısa) ve infradiyen ritim (24 saaatten daha uzun) olarak da tanımlanmaktadır (Reinberg ve Ashkenazi, 2003; Schulz ve Steimer, 2009; Wirz-Justice, 2006).

$\mathrm{Bu}$ ritimler arasından 24 saatlik olan sirkadyen ritim en fazla üzerinde durulan konulardan biri olarak ortaya çıkmaktadır. Sirkadyen ritim retina, retinohipotalamik yol, pineal bez ve suprakiazmatik çekirdeğin uyum içinde çalışması ile düzenlenmektedir (Borjigin, Li ve Snyder, 1999). Gün içerisinde döngümüzü gerçekleştirirken uyku bizim için çok önemlidir. Uyku hormonu olarak bilinen melatonin salınımının başlatılmasında suprakiazmatik çekirdek ve pineal bez en önemli bölgelerdir (Schulz ve Steimer, 2009). 


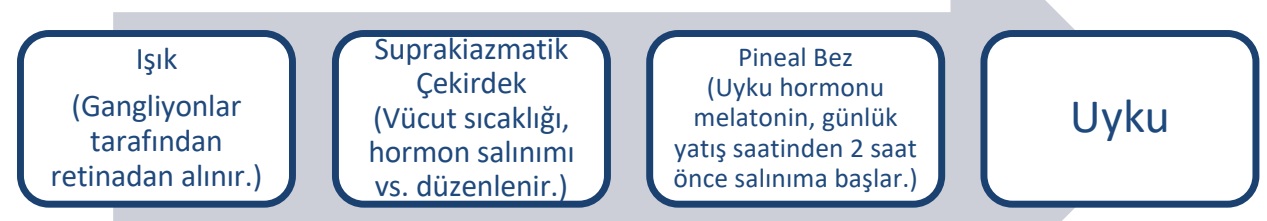

Şekil 1. Sirkadyen ritim.

Mevsimsel değişimlerin kişilerin ruh sağlıkları üzerinde olumsuz etkiler yaratması nedeniyle, mevsimsel değişimler nedeniyle birtakım psikopatolojik semptomlar görülmesi DSM-V'te yer verilen Mevsimsel Duygudurum Bozukluğu olarak tanımlanmaktadır. Mevsimsel değişimlerin kişiler üzerinde tüm y1l boyunca belirtileri görülebilmekle birlikte, majör depresif bozukluğun bir alt alanı olarak özellikle kişilerde sonbahar ve kış aylarında depresif belirtiler yoğun olarak görülmektedir. Kış aylarında belirtilerdeki artış nedeni ile 'kış depresyonu' olarak adlandırılsa da bazı kişilerde bu depresif belirtiler yaz aylarında da görülebilmektedir (Ekinci, Okanlı ve Gözüağca, 2005; Roecklein ve Rohan, 2005; Rosenthal ve ark., 1984).

Bir depresyon türü olarak, mevsimsel duygudurum bozukluğunda görülen semptomlar DSM-V'ye (2013) göre şöyle sıralanmıştır: ümitsizlik, yaşama dair inancının kalmadığı hissi, iştah kaybı, cinsel istekte azalma, ilgilenilen faaliyetlere karşı ilgisizlik hâli, uyku problemleri, yorgunluk hissi, sinirlilik hissi, anksiyete, ölüm ve intihar üzerine yoğunlaşan düşüncelerdir (APA, 2013).

Mevsimsellik üzerine yapılan çalışmaların çoğu, Kuzey Avrupa ülkelerinde gerçekleştirilmektedir. Bu ülkelerde veya bölgelerde çoğunlukla hava kapalı veya karanlık olmaktadır. Araştırmacılar, bu hava koşullarının depresyon vs. gibi psikolojik rahatsızlıklarla ilişkili olduğunu ve intihar oranlarının özellikle kış aylarında bu ülkelerde yaşayan insanlarda daha çok arttığını bildirmektedir (Simrén ve ark., 2002). Ülkenin dünya üzerindeki konumundan kaynaklı olarak mevsimler arası geçişlerde iklim koşulları farklılaşmaktadır ve mevsimsel duygudurum bozukluğu ile ülkenin yer aldığ 1 enlem arasındaki anlamlı ilişkiyi gösteren birçok araştırma bulgusu da mevcuttur (Mersch, Middendorp, Bouhuys, Beersma ve Van den Hoofdakker, 1999a). Cinsiyet açısından incelendiğinde, yetişkin kadınların erkeklere na- 
zaran depresif belirtileri gösterme oranının daha yüksek olduğu gözlenmektedir (Kokras ve Dalla, 2017; Roecklein ve Rohan, 2005).

$\mathrm{Bu}$ olguya ilişkin gözlemler ve araştırma sonuçlarının yanında, Mevsimsel Duygudurum Bozukluğu'nun tedavisi amacıyla birçok farklı tedavi tekniği kullanılmaktadır. Örneğin, melatonin tedavisi, ışık terapisi, psikofarmakolojik ilaçlar ve psikoterapi bu tedavilerden bazılarıdır (Rohan ve ark., 2015). Bununla beraber, bu bozuklukta en etkili olan ve en s1k kullan1lan yöntem 1şı terapisidir. Özellikle, Kuzey Avrupa bölgelerinde sıklıkla kullanılan bu yöntemde 1şı miktarı düzenlenen özel lambalar ile ayarlanmakta ve bu şekilde kişinin uyku ve uyanma düzenine yönelik değişim sağlanmaktadır (Roecklein ve Rohan, 2005).

\section{Öznel İyi Oluş}

Psikoloji alanyazınında ağırlıklı olarak II. Dünya Savaşı'ndan itibaren dönemin şartları göz önünde bulundurularak psikolojik rahatsızlıklar ve insanı mutsuz yapan durumlar araştırma konusu olarak ele alınmıştır. Doksanlı yıllara gelindiğinde, araştırmacılar pozitif duygulanım veya uzun süreli duygulanım olan mutluluk ile ilgilenmeye başlamışlardır. Mutluluk psikolojide öznel iyi oluş olarak bazen de öznel iyi oluş başlığı altında incelenmektedir. Öznel iyi oluş veya mutluluk, ise kişilerin yaşamlarına yönelik bir değerlendirme yaptıklarında, olumlu duyguları yaşadıkları anların olumsuz duygular taşıyan anılardan daha fazla olması (duygusal boyut) ve yaşam doyumunun (bilişsel boyut) yüksek olması olarak tanımlanmaktadır (Diener, Suh ve Oishi, 1997; Myers ve Diener, 1995; Ryan ve Deci, 2001).

Pozitif psikolojide alanyazın yeni gelişmekte olmasına rağmen, öznel iyi oluşu açıklayan birçok kuram vardır. Bunlar; amaç kuramı, dinamik denge kuramı, tabandan tavana ve tavandan tabana yaklaşımı, Csikzentmihalyi’nin akış kuramı, bağ kuramları, yargı kuramları ve beklenti düzeyi kuramidir (Hamurcu, 2011).

Öznel iyi oluş kavramına yönelik gerek yurtdışında gerekse ülkemizde çok sayıda araştırmalar yapılmıştır. Bu makalede konu geniş ve yer az oldugundan dolayı özellikle mevsimsellik, depresyon ve anksiyete ile ilişkisini inceleyen çalışmalara yer verilmiştir. Üniversite öğrencilerinin yaşam doyumu ve duygudurumları üzerine yapılan bir çalışmada, Diener ve Seligman (2002) 222 üniversite öğrencisinden oluşan bir katılımcı grubunda yaklaşık 51 gün boyunca ve ayın belirli dönemlerinde yaşam doyumu ve duygudurum ölçümleri almıştır. Araştırma sonucunda, yaşam doyumu ölçümünde 35 üze- 
rinde 30 olan ve en mutlu olan katılımcilar olarak belirlenen öğrencilerin intihar düşünceleri olmadığı, olumsuz anılara kıyasla olumlu anıları daha çok hatırladıkları bulunmuştur. Öte yandan, çok mutsuz olarak belirlenen katılımcıların ise yaşam doyumlarının düşük olduğu görülmüştür.

Eagles, Mcleod ve Douglas (1997), yaş düzeyi yüksek 1466 yetişkin ile yaptıkları bir çalışmada 21 ay boyunca depresyon ve anksiyete puanları üzerinden ölçüm almışlardır. Araştırma sonunda, kış aylarında depresyon ve anksiyete puanlarının anlamlı olarak yükseldiği ve katılımcıların psikolojik iyi oluş düzeyleri düştüğü görülmüştür.

Alanyazında yer alan çalışmalar incelendiğinde, mevsimsellik ve öznel iyi oluş ilişkisine yönelik yapılan çalışmalarda, sirkadyen ritim ve uyku düzeni le öznel iyi oluş arasındaki ilişkinin incelendiği çalışmalar görülmektedir (Murray, Allen ve Trinder, 2002). Uyku problemi yaşayan veya açık havada kış aylarında daha az vakit geçirme gibi çevresel faktörlerin de öznel iyi oluş ile ilişkisi çeşitli araştırma bulguları ile ortaya konmuştur (De Vries ve ark., 2003; Hartig, Catalano ve Ong, 2007; Oyane ve ark., 2008).

Türkiye'de mevsimsellik konusunda yapılan en kapsamlı çalışmalardan biri Yöney, Taybili ve Göktepe (1995) tarafından yapılmıştır. Bu çalışmada yer alan 228 öğrenci, uygulanan mevsimsel değişim değerlendirme formunu doldurmuşlardır ve bulgulara göre; öğrencilerin \%39.5'i mevsimsel değişimlerden oldukça etkilendiğini belirtmiştir. Ayrıca, katılımcılar kendilerini en iyi hissettikleri dönem olarak ilkbahar ve yaz mevsimlerini belirtmişlerdir. Mevsimselliğin depresyon ve anksiyete semptomları üzerindeki etkisinin incelendiği bir çalışmada 2168 katılımcı yer almıştır. Bulgular incelendiğinde, mevsimsel değişimlerin depresyon ve anksiyete semptomlarını tetiklediği görülmüştür (Winthorst ve ark., 2014).

Mevsimsel duygudurum bozukluğuna yönelik en etkili tedavi yöntemi olan 1şık terapisinin depresyon ve anksiyete semptomlarını önleyici bir antidepresan etkisi olduğu da yapılan araştırmalar sonucunda ortaya çıkmıştır. Dört hafta boyunca süren ve 89 katılımcı ile yürütülen çalışmada, semptomların \%50 oranında azaldığı görülmüştür (Jurvelin ve ark., 2014).

Alanyazın incelendiğinde, mevsimsel değişimlerin ruh sağlı̆̆ımız üzerindeki etkilerine dikkat çekilmesine rağmen Türkiye'de bu konuda yeterli sayıda çalışma yapılmadığı görülmüştür. Bu noktadaki eksikliği gidermek adına, mevsimsel değişimlerin depresyon ve anksiyete semptomları ile 
ilişkisini Türk örneklem grubu üzerinden değerlendirmeye ek olarak, öznel iyi oluş, yani mutluluk, gibi olumlu duygular ile ilişkisini inceleyen ilk Türk çalışmasının gerçekleştirilmesi amaçlanmıştır. Bu çalışmada, mevsimsellik ve öznel iyi oluş ilişkisi ile bu ilişkide depresyon ve anksiyetenin aracı rolü, Bağ Kuramı ve Duygusal Kararsızlık Kuramı çerçevesinde ele alınmıştır.

Bağ kuramı, kişilerin yaşadıkları olaylar veya durumlar arasında olumlu veya olumsuz yönden bir ilişki kurma ihtiyacını incelemektedir. Kişi, bir olayı veya durumu ilk yaşadığı ân nasıl bir ilişki kurarsa, daha sonra bu olay veya durumu tekrar yaşadığında aynı bağ devreye girmektedir. Bağ Kuramı'na göre, aslında bir doğa olayı olan mevsimsel değişimler nötr bir durumda olmasına rağmen hava koşulları veya olumsuz tutum geliştirmeleri sebebiyle bazı insanlar bu olayları olumsuz olarak algılamaktadır. Serotonin ve melatonin salınımlarındaki değişiklikler gibi insan vücudunda meydana gelen fizyolojik değişimler de bu yorumlamayı etkilemektedir (Tülek, 2011). Duygusal Kararsızlık Kuramı'na göre ise, bireyler olumlu veya olumsuz bir olay yaşadıklarında o günkü hava koşulları ile de bir bağlantı kurabilir ve o mevsime yönelik olumlu veya olumsuz yüklemeler yapabilmektedirler (Taylor, Peplau ve Sears, 2010). Bu nedenle, mevsimsel değişimlerin, kişilerin psikolojik semptomları ve öznel iyi oluş düzeylerini etkilediği düşünülmektedir.

Alanyazında yer alan çalışmalar incelendiğinde, mevsimselliğin kişileri oldukça etkilediği görülmüş ve yapılan çalışmaların eksikliğini gidermek ve katkıda bulunmak adına, mevsimsellik ve öznel iyi oluş ilişkisi depresyon ve anksiyete boyutları da araştırma modeline eklenerek incelenmiştir.

\section{Araştırmanın Modeli}

\section{Yöntem}

$\mathrm{Bu}$ çalışmada, ilişkisel tarama modeline bağlı olarak, iki veya daha fazla değişken arasındaki ilişki incelenmiştir. Bir diğer analiz modeli ise, mevsimsellik ve öznel iyi oluş arasındaki ilişkide psikolojik semptomların aracı rolünün incelenmesinde uygulanan aracılık analizidir.

\section{Araştırmanın Örneklemi}

Araştırmanın evrenini üniversite öğrencileri oluşturmaktadır. Bu ça1ışmada, Abant İzzet Baysal Üniversitesi'nde örgün öğretime devam etmekte olan toplam 227 öğrenci seçkisiz olarak seçilmiştir. Öğrencilerin cinsiyete göre dağılımları incelendiğinde, örneklemin 168 'inin kız (\%74) ve 59'unun erkek (\%26) oldukları görülmektedir. Ayrıca, öğrencilerin öğrenim gördük- 
leri bölümlere göre dağılımları ise, aşağıdaki Tablo 1'de gösterilmiştir.

Tablo 1. Öğrencilerin Bölümlerine Göre Dağılımları

\begin{tabular}{lcc}
\hline Bölüm & N & \% \\
\hline Psikoloji & 148 & 65.2 \\
Rehberlik ve Psikolojik Danışmanlık & 44 & 19.4 \\
Zihinsel Engelliler Öğretmenliği & 35 & 15.4 \\
\hline Toplam & 227 & 100 \\
\hline
\end{tabular}

\section{Kullanılan Ölçme Araçları}

Çalışmada Demografik Bilgi Formu, Mevsimsel Gidiş Değerlendirme Formu (MGDF), Öznel İyi Oluş Ölçeği (OIO) ve Kısa Semptom Envanteri (KSE) kullanılmıştır.

Mevsimsel Gidiş Değerlendirme Formu (MGDF): Mevsimsel değişimlerin kişiler üzerindeki etkisinin incelenmesi amaciyla geliştirilen Mevsimsel Gidiş Değerlendirme Formu (Seasonal Pattern Questionary-SPAQ), Rosenthal ve arkadaşları tarafindan 1987 yılında geliştirilmiştir. Ölçeğin Türkçe uyarlaması ise, Noyan, Elbi ve Korukoğlu tarafından (2000) yapılmıştır. Ölçeğin uyarlaması kapsamında mevsimsellik puanı veren alt1 maddesinin (uyku miktarı, sosyal yaşantı, duygudurum, kilo, iştah ve enerji düzeyi) Cronbach Alfa değeri .67 bulunmuştur. Bu araştırma kapsamında yapılan faktör analizinde ise, KMO değeri .72, iç tutarlılık (Cronbach Alfa) katsayısı ise .72 olarak bulunmuştur.

Öznel İyi Oluş Ölçeği: Tuzgöl-Dost (2004) tarafından geliştirilen Öznel İyi Oluş ölçeği, kişilerin olumlu ve olumsuz duyguları ile kişilerin yaşam doyumlarına yönelik bilgi vermesi amacıyla uygulanan bir ölçektir. Tuzgöl-Dost tarafından yapılan güvenirlik analizi sonuçlarına göre, ölçeğin Cronbach Alfa güvenirlik katsayısı .93 olarak bulunmuştur. Bu çalışmada ölçek maddelerine yapılan faktör analizi bulgularına göre, KMO değeri .91, ölçeğin iç tutarlılık (Cronbach Alfa) katsayısı ise .92 olarak bulunmuştur.

Kısa Semptom Envanteri: Kişilerin genel psikopatojilerinin incelenmesi amacıyla, Derogatis (1992) tarafından geliştirilen Kısa Semptom Envanteri, toplam 53 maddeden oluşmaktadır. Ölçeğin Türkçe uyarlaması ise, Şahin ve Durak tarafından 1994 yılında yapılmıştır. Ölçeğin ilk versiyonu, toplamda dokuz alt boyutu (somatizasyon, obsesif-kompülsif bozukluk, kişilerarası duyarl1l1k, depresyon, anksiyete, hostilite, fobik anksiyete, paranoid düşünceler ve psikotisizm), üç global indeks (rahatsızlık ciddiyeti indeksi, belirti 
toplamı ve semptom rahatsızlık indeksi) ve ek maddelerden oluşmaktadır ancak Türkçe uyarlamasının ardından, Şahin ve Durak tarafından beş faktörden (depresyon, anksiyete, olumsuz benlik, somatizasyon ve hostilite) oluştuğu görülmüştür. Alt ölçeklerin iç tutarlılık (Cronbach Alfa) katsayılarının .87), yapılan faktör analizi sonucuna göre ise KMO değeri ise .96 olarak bulunmuştur. $\mathrm{Bu}$ araştırmada ölçeğin, depresyon ve anksiyete alt boyutlarını içeren maddelerinden yararlanılmıştır.

\section{Bulgular}

Mevsimsellik puanlarına göre cinsiyet açısından bir fark bulunup bulunmadığ incelenmiş ve tabloda yer alan bilgilere göre, kı (Ort. $=10.62$, $\mathrm{ss}=4.15)$ ve erkek öğrencilerin mevsimsellik puan ortalamaları (Ort. $=9.86$, $\mathrm{ss}=4.50)$ arasındaki farkın .05 düzeyinde istatistiksel olarak anlamsız olduğu görülmüştür [t(223)=1.17, $p>.05]$. Bu sonuca dayanarak k1z ve erkek öğrencilerin mevsimsellik puanları üzerinde cinsiyetin anlamlı bir etkisinin bulunmadığ 1 belirlenmiştir.

Öznel iyi oluş puanları açısından cinsiyetler arası karşılaştırma yapıldığında, analiz sonucunda elde edilen bulgulara göre, kız öğrencilerin öznel iyi oluş puan ortalamaları (Ort.=164.13, ss=32.75) ile erkek öğrencilerin puan ortalamaları (Ort. $=160.33$, ss $=27.59$ ) arasındaki farkın .05 düzeyinde anlamlı olmadığ görülmüştür [ $\mathrm{t}(208)=.78, p>.05]$. Bu nedenle, k1z ve erkek öğrencilerin öznel iyi oluş puanları üzerinde cinsiyetin anlamlı etkisi bulunmamıştır.

Psikolojik semptomlar açısından cinsiyetler arası bir karşılaştırma yapıldığında ise, göre kız ve erkek öğrencilerin depresyon ve anksiyete, puan ortalamalarından kıların (Ort. $=13.58, \mathrm{ss}=10.80)$ ve erkeklerin (Ort.=17.76, $\mathrm{ss}=11.61)$ anksiyete puan ortalamaları arasında istatistiksel olarak anlamlı bir fark vardir[t(93.72)=-2.40].

Tablo 2. Cinsiyete Göre Depresyon ve Anksiyete Puanları

\begin{tabular}{llcccccc}
\hline & Cinsiyet & $\mathbf{N}$ & Ort. & ss & Sd & t & $\boldsymbol{p}$ \\
\hline Depresyon & K1z & 167 & 15.50 & 11.86 & 223 & -.74 & $>.05$ \\
& Erkek & 58 & 16.81 & 10.82 & & & \\
\hline Anksiyete & Kiz & 166 & 13.58 & 10.80 & 93.72 & $-2.40^{*}$ & $<.05$ \\
& Erkek & 58 & 17.76 & 11.61 & & & \\
\hline
\end{tabular}

${ }^{*} p<.05, * * p<.01$

Alanyazında yer alan bulgular 1şığında, mevsimsellik ve öznel iyi oluş arasında negatif ve anlamlı bir ilişki bulunmakta ve çalışma bulguları da bu 
bilgiyi destekler nitelikte, öğrencilerin mevsimsellik puanları ile öznel iyi oluş düzeyleri arasında -.26 düzeyinde negatif ve anlamlı bir ilişki saptanmıştır $(p<.05)$. Bu sonuca göre, mevsimsellik puanı arttıkça öğrencilerin öznel iyi oluş düzeylerinin düştüğü görülmektedir. Ayrıca, öğrencilerin mevsimsellik puanları ve öznel iyi oluş ölçeğinin alt boyutları arasındaki ilişki incelendiğinde, klyaslama $(\mathrm{r}=-.15, p<.05)$, olumlu-olumsuz duygu $(\mathrm{r}=-.25, p<.05)$, amaç $(\mathrm{r}=-.18, p<.05)$, iyimserlik $(\mathrm{r}=-.21, p<.05)$, etkinlik $(\mathrm{r}=-.24, p<.05)$, arkadaşl1k $(\mathrm{r}=-.19, p<.05)$, gelecek $(\mathrm{r}=-.16, p<.05)$, imrenme $(\mathrm{r}=-.24, p<.05)$, baş etme $(\mathrm{r}=-.17, p<.05)$ ve karamsarlık $(\mathrm{r}=-.15, p<.05)$ değişkenleri ile arasında negatif yönde ve anlamlı bir ilişki bulunmuştur.

Mevsimsellik ve öznel iyi oluş arasındaki ilişkide depresyon ve anksiyete alt boyutlarının aracılık rolünün incelenmesi amacıyla değişkenler arasındaki ilişki Pearson korelasyon katsayısı ile hesaplanmıştır. Analiz sonucunda elde edilen veriler Tablo 3 'te yer almaktadır.

Tablo 3. Mevsimsellik ve Öznel İyi Oluş İlişkisi

\begin{tabular}{lcc}
\hline & Mevsimsellik & Öznel İyi Oluş \\
\hline Mevsimsellik & 1 & $-.26^{* *}$ \\
Öznel İyi Oluş & $-.26^{* *}$ & 1 \\
\hline${ }^{*} p<.05,{ }^{* *} p<.01$ & &
\end{tabular}

Mevsimsellik, öznel iyi oluş ve psikolojik semptomlar arasında anlamlı düzeyde korelatif ilişki görülmesi nedeniyle aracılık analizi yapılmış ve psikolojik semptomlar teker teker analize dahil edilmiştir. Uygulanan aracılık analizinin ardından yapılan Sobel testi sonucunda depresyon ve anksiyetenin analize eklenmesi ile mevsimsellik puanında görülen düşüşün anlamlı olduğu görülmüştür. Bu nedenle, psikolojik semptomlar, mevsimsellik ve öznel iyi oluş ilişkisinde aracı değişkenler olarak bulunmuştur.

Tablo 4. Mevsimsellik, Öznel İyi Oluş, Depresyon ve Anksiyete Arasındaki İlişki

\begin{tabular}{lcccc}
\hline & Mevsimsellik & Öznel İyi Oluş & Depresyon & Anksiyete \\
\hline Mevsimsellik & 1 & & & \\
Öznel İyi Oluş & $-.26^{* *}$ & 1 & & \\
Depresyon & $.42^{* *}$ & $-.53^{* *}$ & 1 & \\
Anksiyete & $.41^{* *}$ & $-.52^{* *}$ & $.85^{* *}$ & 1 \\
${ }^{*} p<.05,{ }^{* *} p<.01$ & & & &
\end{tabular}




\section{Depresyonun Aracı Rolünün İncelenmesi}

Mevsimsellik ve öznel iyi oluş arasındaki anlamlı ilişki $(B=-.26)$, depresyon değişkeninin modele eklenmesi ile $(\mathrm{B}=-.05)$ düşmektedir. Mevsimsellik ve depresyon $(\mathrm{B}=.42)$ ile depresyon ve öznel iyi oluş $(\mathrm{B}=-.53)$ arasındaki ilişki incelenmiştir. $\mathrm{Bu}$ düşüşün anlamlılığını test etmek amaciyla yapılan Sobel testi sonucuna göre, düşüşün anlamlı $(\mathrm{Z}=-4.94, p<.00001)$ olduğu görülmüş ve depresyon aracı değişken olarak kabul edilmiştir.

Tablo 5. Depresyonun Aracı Rolü

\begin{tabular}{lccccc}
\hline & B & Standart Hata & Beta & t & $\boldsymbol{p}$ \\
\hline Model 1 & & & & & \\
Sabit & 182.64 & 5.46 & & 33.42 & .00 \\
Mevsimsellik & -1.88 & .48 & -.26 & -3.87 & .00 \\
\hline Model 2 & & & & & \\
Sabit & 188.47 & 4.86 & & 38.78 & .00 \\
Mevsimsellik & -.38 & .47 & -.05 & -.81 & .42 \\
Depresyon & -1.36 & .17 & -.51 & -7.99 & .00 \\
\hline${ }^{*}<<.05,{ }^{* *} p<.01$ & & & & &
\end{tabular}

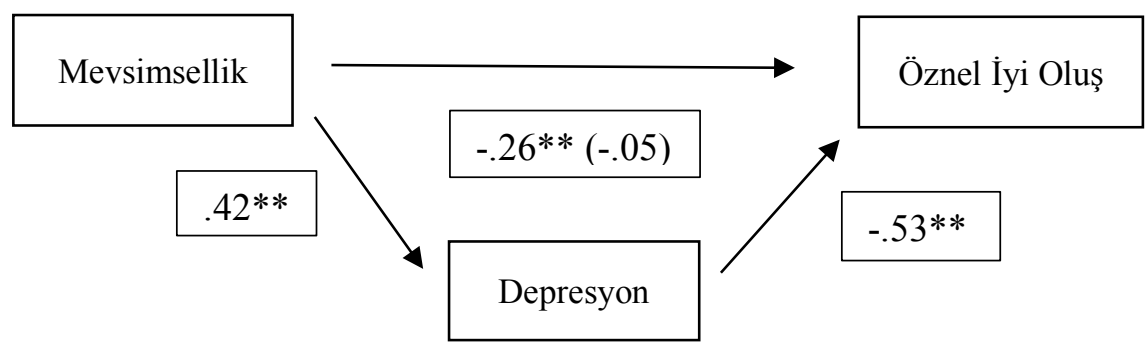

Şekil 2. Depresyonun aracı rolü.

\section{Anksiyetenin Aracı Rolünün İncelenmesi}

Mevsimsellik ve öznel iyi oluş arasındaki anlamlı ilişki $(B=-.26)$, anksiyete değişkeninin modele eklenmesi ile $(\mathrm{B}=-.07)$ düşmektedir. Mevsimsellik ve anksiyete $(\mathrm{B}=.40)$ ile anksiyete ve öznel iyi oluş $(\mathrm{B}=-.52)$ arasındaki ilişki, bu düşüşün anlamlılığını test etmek amacıyla Sobel testi uygulanarak incelenmiştir. Analiz sonucunda elde edilen bulgulara göre, düşüşün anlamlı olduğu görülmüş $(Z=-4.56, p<.00001)$ ve anksiyete aracı değişken olarak kabul edilmiştir. 
Tablo 6. Anksiyetenin Aracı Rolü

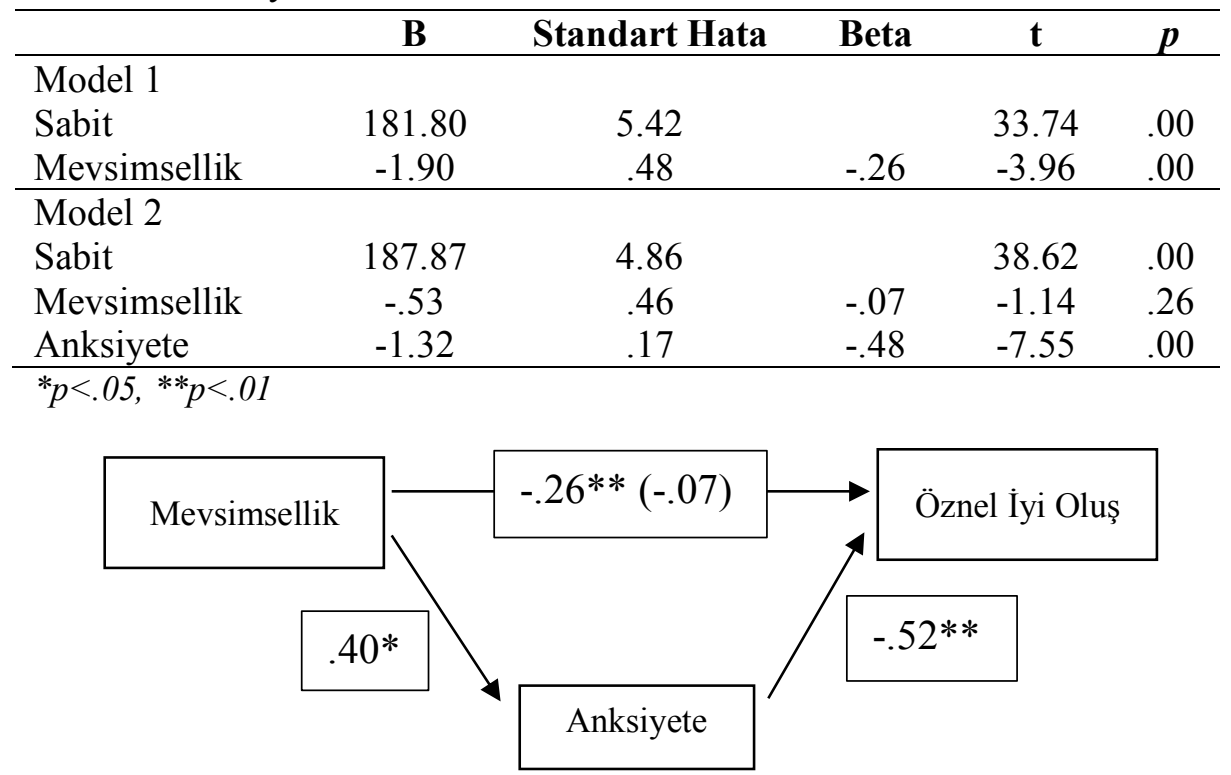

Şekil 3. Anksiyetenin aracı rolü.

Mevsimsellik ve öznel iyi oluş düzeyi arasındaki ilişkinin incelendiği bu çalışmada, hipotezlerin doğruluğu bulgular bölümünde verilen bilgiler doğrultusunda kanıtlanmıştır. Çalışmada yer alan mevsimsellik, öznel iyi oluş ve psikolojik semptom değişkenleri arasındaki ilişki Pearson korelasyon katsayılarının hesaplanması ile görülmüş ve .05 düzeyinde anlamlı ilişkiler gözlenmiştir. Açıkladığı varyanslar açısından değişkenler incelendiklerinde, mevsimsellik değişkeninin öznel iyi oluş düzeyini .05 düzeyinde açıkladığ 1 görülmüştür. Ayrıca, psikolojik semptomların mevsimsellik ve öznel iyi oluş arasındaki ilişkide aracı değişkenler oldukları bulgularda yer alan bilgiler doğrultusunda doğrulanmıştır.

\section{Tartışma}

Üniversite öğrencilerinden alınan bilgiler doğrultusunda, öğrencilerin mevsimsellik puanlarında cinsiyete göre anlamlı bir fark görülmemiştir. Alanyazında yer alan çalışmalar incelendiğinde, kadınların erkeklere nazaran mevsimsel değişimlerden daha fazla etkilendikleri görülmektedir (Eagles ve ark., 2002; Mersch ve ark., 1999b; Neumeister, Konstantinidis, Praschak-Rieder, Willeit, Hilger, Stastny ve Kasper, 2001). Ancak mevsimsel duygudurum bozukluğu yaşayan bireylerle yapılan bazı çalışma sonuçlarına göre ise, majör depresif bozukluğun eşlik ettiği mevsimsel duygudurum 
bozukluğu daha çok erkeklerde görülürken, minör depresif bozukluğun eşlik ettiği mevsimsel duygudurum bozukluğuna ise kadınlarda daha sık rastlanmaktadır (Blazer, Kessler ve Swartz, 1998). Bizim çalışma bulgularımız ise, Han ve arkadaşları (2000) tarafından yapılan çalışma sonuçları ile paralel bulunmuş, cinsiyet açısından mevsimsellik puanları arasında anlamlı bir farka rastlanmamıştır.

Üniversite öğrencilerinin öznel iyi oluş düzeylerinin cinsiyete göre farklılık gösterip göstermediği araştırılmış, kız ve erkek öğrenciler arasında anlamlı bir fark bulunmamıştır. Araştırmada elde edilen bulguların alanyazında yer alan birçok araştırma sonucu ile tutarlı olduğu görülmüştür (Tuzgöl-Dost, 2004; Kermen ve Sarı, 2014; Tümkaya, 2011). Bu sonuca ek olarak, cinsiyetin öznel iyi oluş düzeyi üzerinde anlamlı etkisinin olduğunu gösteren bazı araştırma sonuçları da mevcuttur (Derdikman-Eiron ve ark., 2011; Lyubomirsky, Sheldon ve Schkade, 2005).

Üniversite öğrencilerinin psikolojik semptom puanlarının cinsiyete göre farklılaşıp farklılaşmadığı incelendiğinde, depresyon düzeyleri açısından kız ve erkek öğrenciler arasında anlamlı fark bulunmamış fakat, anksiyete puanları açısından bir karşılaştırma yapıldığında, anlamlı fark tespit edilmiştir. Sonuçlara göre, kız öğrencilerin (Ort. $=13.58, \mathrm{ss}=10.80)$ anksiyete puan ortalamasının erkeklerin (Ort. $=17.76$, ss=11.61) puan ortalamasından anlamlı olarak düşük olduğu görülmüştür.

Mevsimsellik ve öznel iyi oluş ilişkisinde psikolojik semptomların aracı rolünün alanyazında yer alan önceki çalışmalarda incelenmemiş olması nedeniyle, mevsimsellik, depresyon ve anksiyete ile öznel iyi oluş, depresyon ve anksiyete değişkenleri arasındaki ilişkiyi inceleyen çalışmalara yer verilmiştir. Ancak, mevsimsel değişimlere bağlı olarak kişilerin öznel iyi oluş düzeylerinde düşüş görülmesi nedeniyle, psikolojik semptomlar bağlamında mevsimsellik ve öznel iyi oluş arasındaki ilişki ayrıntılı olarak bu araştırma ile ele alınmıştır. Mevsimsel değişimin bireyin duygudurumunu etkilediği birçok araştırma bulgusu ve bizim araştırma bulgularımız ile tutarlıdır (Gunnlaugsson, Kristjánsson, Einarsdóttir ve Sigfúsdóttir, 2011; Wirz-Justice, 2008). Bireyler özellikle sonbahar ve kış aylarında kendilerini daha depresif ve kaygılı hissettiklerini beyan etmişler ve bu bulgular alanyazında yer alan birçok çalışma ve 'kış depresyonu' kavramı ile de uyumluluk göstermektedir (Rosenthal ve ark., 1984; Terman ve Terman, 2005). Bu nedenle, bu değişime kolay adapte olamayan, değişimin sonuçlarından dişarıda 
daha az vakit geçirme, daha fazla kapalı alanda kalma, daha az gün 1şı̆̆ alma ve soğuk havaların vücutta yarattığı fizyolojik tepkilerden daha çok etkilenen bireylerin alanyazınla tutarlı olarak öznel iyi oluş, yani mutluluk düzeylerinde de bir düşüş gözlenmiştir. Çalışmamızda elde edilen anlamlı ilişkiler ve değişkenlerin aracı rolüne ilişkin bulgular temel alınarak, diğer araştırmacıların bu çalışmanın devamını getirebilecekleri önerilmektedir (Chellappa, Schröder ve Cajochen, 2009; Derdikman-Eiron ve ark., 2011; Grandin, Alloy ve Abramson, 2006; Gunnlaugsson ve ark., 2011; Güney, Kalafat ve Boysan, 2010; Ketenci, Kır, Başbulut ve Beyhun, 2013; Rosenthal ve ark., 1984; Serin, Serin ve Özbaş, 2010; Terman ve Terman, 2005; Wirz-Justice, 2008).

\section{Sonuç}

Bu çalışma, Türkiye'de mevsimsellik ve öznel iyi oluş ilişkisinin incelendiği ilk çalışma olma özelliğini taşıması açısından oldukça önemlidir. Çalışmada bulunan bulgular ışığında, alanyazınla tutarlı olarak mevsimsel değişimlerden etkilenme düzeyi ile bireylerin mutluluk düzeyleri arasında negatif ilişki vardır. Bu ilişkide bireylerde görülen depresyon ve anksiyete semptomları dahil olduğunda ise, aradaki ilişki düşmektedir.

Günümüzde en sık incelenen konulardan biri olan iyi oluş kavramı, hem fiziksel hem de ruhsal iyi olma halini kapsamaktadır. Araştırmada incelenen öznel iyi oluş, yani mutluluk kavramı ise, bireylerin hayatlarından aldıkları doyumu etkilemekte, ruhsal hastalıklara yakalanma riskin azaltmakta ve olumlu kişilerarası ilişkiler kurulmasını desteklemektedir. Bu nedenle, mevsim değişimlerine bağlı olarak görülen değişimler ile öznel iyi oluş arasındaki yüksek düzeyde negatif ve anlamlı ilişkiyi kanıtlayan bu bulgular, gelecek araştırmalara 1şık tutmaktadır.

\section{Kaynakça}

American Psychiatric Association. (2013). DSM 5. American Psychiatric Association.

Arendt, J. (2012). Biological rhythms during residence in polar regions. Chronobiology International, 29(4), 379-394.

Bakım, B., Karaahmet, E., Altınbaş, K. ve Oral, T. (2013). Winter sale on lithium levels: The impact of seasonality. Bulletin of Clinical Psychopharmacology, 23(4), 315-319.

Bjorvatn, B. ve Pallesen, S. (2009). A practical approach to circadian rhythm sleep disorders. Sleep Medicine Reviews, 13(1), 47-60. 
Blazer, D. G., Kessler, R. C. ve Swartz, M. S. (1998). Epidemiology of recurrent major and minor depression with a seasonal pattern. The national comorbidity survey. The British Journal of Psychiatry, 172(2), 164-167.

Borjigin, J., Li, X. ve Snyder, S. H. (1999). The pineal gland and melatonin: Molecular and pharmacologic regulation. Annual Review of Pharmacology and Toxicology, 39(1), 53-65.

Chellappa, S. L., Schröder, C. ve Cajochen, C. (2009). Chronobiology, excessive daytime sleepiness and depression: Is there a link? Sleep Medicine, 10(5), 505-514.

Derdikman-Eiron, R., Indredavik, M. S., Bratberg, G. H., Taraldsen, G., Bakken, I. J. ve Colton, M. (2011). Gender differences in subjective well-being, self esteem and psychosocial functioning in adolescents with symptoms of anxiety anddepression: Findings from the nordtrøndelag health study. Scandinavian Journal of Psychology, 52(3), 261-267.

Derogatis, L. R. (1992). SCL-90-R: Administration, scoring and procedures manual-II for the R(evised) version and other instruments of the psychopathology rating scale series. Baltimore: Clinical Psychometric Research.

De Vries, S., Verheij, R. A., Groenewegen, P. P. ve Spreeuwenberg, P. (2003). Natural environments-healthy environments? An exploratory analysis of the relationship between greenspace and health. Environment and Planning, 35(10), 1717-1732.

Diener, E. D., Emmons, R. A., Larsen, R. J. ve Griffin, S. (1985). The satisfaction with life scale. Journal of personality assessment, 49(1), 71-75.

Diener, E., Suh, E. ve Oishi, S. (1997). Recent findings on subjective well being. Indian Journal of Clinical Psychology, 24(1), 25-41.

Diener, E. ve Seligman, M. E. (2002). Very happy people. Psychological Science, 13(1), 81-84.

Eagles, J. M., Mcleod, I. H. ve Douglas, A. S. (1997). Seasonal changes in psychological well-being in an elderly population. The British Journal of Psychiatry, 171(1), 53-55.

Eagles, J. M. Andrew, J. E., Wileman, S. M., Howie, F. L., Cameron, I. M. ve Naji, S. A. (2002). Seasonal affective disorder, and social deprivation in aberdeen. Journal of Affective Disorders, 70(3), 337-340.

Ekinci, M., Okanlı, A. ve Gözüağca, D. (2005). Mevsimsel depresyonlar ve 
baş etme yolları. Anadolu Hemşirelik ve Sağllk Bilimleri Dergisi/Journal of Anatolia Nursing and Health Sciences, 8(1), 109-112.

Grandin, L. D., Alloy, L. B. ve Abramson, L. Y. (2006). The social zeitgeber theory, circadian rhythms, and mood disorders: Review and evaluation. Clinical Psychology Review, 26(6), 679-694.

Gunnlaugsson, G., Kristjánsson, Á. L., Einarsdóttir, J. ve Sigfúsdóttir, I. D. (2011). Intrafamilial conflict and emotional well-being: A population based study among icelandic adolescents. Child Abuse \& Neglect, 35(5), 372-381.

Güney, S., Kalafat, T. ve Boysan, M. (2010). Dimensions of mental health: Life satisfaction, anxiety and depression: A preventive mental health study in Ankara University students population. Procedia-Social and Behavioral Sciences, 2(2), 1210-1213.

Hamurcu, H. (2011). Ergenlerin yetkinlik inançları ve psikolojik iyi oluşlartnı yordamada psikolojik ihtiyaçlar. Yayınlanmamış doktora tezi, Selçuk Üniversitesi Eğitim Bilimleri Enstitüsü.

Han, L., Wang, K., Du, Z., Cheng, Y., Simons, J. S. ve Rosenthal, N. E. (2000). Seasonal variations in mood and behavior among Chinese medical students. American Journal of Psychiatry, 157(1), 133-135.

Hartig, T., Catalano, R. ve Ong, M. (2007). Cold summer weather, constrained restoration and the use of antidepressants in Sweden. Journal of Environmental Psychology, 27(2), 107-116.

Jurvelin, H., Takala, T., Nissilä, J., Timonen, M., Rüger, M., Jokelainen, J. ve Räsänen, P. (2014). Transcranial bright light treatment via the ear canals in seasonal affective disorder: A randomized, double-blind dose-response study. BMC psychiatry, 14(1), 1-25.

Ketenci, H. Ç., Kır, M. Z., Başbulut, A. Z. ve Beyhun, N. E. (2013). Erzurum adli tıp şube müdürlüğüne müracaat eden olguların değerlendirilmesi. Adli Tip Dergisi, 27(2), 87-93.

Kokras, N. ve Dalla, C. (2017). Preclinical sex differences in depression and antidepressant response: Implications for clinical research. Journal of Neuroscience Research, 95(12), 731-736.

Lyubomirsky, S., Sheldon, K. M. ve Schkade, D. (2005). Pursuing happiness: The architecture of sustainable change. Review of General Psychology, 9(2), 111-131.

Mersch, P. P. A., Middendorp, H. M., Bouhuys, A. L., Beersma, D. G. ve van den Hoofdakker, R. H. (1999a). The prevalence of seasonal affective disorder in The Netherlands: a prospective and retrospective study 
of seasonal mood variation in the general population. Biological psychiatry, 45(8), 1013-1022.

Mersch, P. P. A., Middendorp, H. M., Bouhuys, A. L., Beersma, D. G. ve van den Hoofdakker, R. H. (1999b). Seasonal affective disorder and latitude: A review of the literature. Journal of Affective Disorders, 53(1), 35-48.

Methippara, M. M., Bashir, T., Kumar, S., Alam, N., Szymusiak, R. ve McGinty, D. (2009). Salubrinal, an inhibitor of protein synthesis, promotes deep slow wave sleep. American Journal of Physiology-Regulatory, Integrative and Comparative Physiology, 296(1), 178-184.

Murray, G., Allen, N. B. ve Trinder, J. (2002). Mood and the circadian system: Investigation of a circadian component in positive affect. Chronobiology International, 19(6), 1151-1169.

Myers, D. G. ve Diener, E. (1995). Who is happy?. Psychological Science, 6(1), 10-19.

Neumeister, A., Konstantinidis, A., Praschak-Rieder, N., Willeit, M., Hilger, E., Stastny, J. ve Kasper, S. (2001). Monoaminergic function in the pathogenesis of seasonal affective disorder. The International Journal of Neuropsychopharmacology, 4(4), 409-420.

Noyan, M. A., Elbi, H. ve Korukoğlu, S. (2000). Mevsimsel gidiş değerlendirme formu (MGDF): Güvenilirlik araştırması. Anadolu Psikiyatri Dergisi, 1(2), 69-77.

Oyane, N. M., Bjelland, I., Pallesen, S., Holsten, F. ve Bjorvatn, B. (2008). Seasonality is associated with anxiety and depression: The Hordaland health study. Journal of Affective disorders, 105(1), 147-155.

Reinberg, A. ve Ashkenazi, I. (2003). Concepts in human biological rhythms. Dialogues in Clinical Neuroscience, 5(4), 327-342.

Roecklein, K. A. ve Rohan, K. J. (2005). Seasonal affective disorder: An overview and update. Psychiatry (Edgmont), 2(1), 20-26.

Rohan, K. J. Mahon, J. N., Evans, M., Ho, S. Y., Meyerhoff, J., Postolache, T. T. ve Vacek, P. M. (2015). Randomized trial of cognitive-behavioral therapy versus light therapy for seasonal affective disorder: Acute outcomes. American Journal of Psychiatry, 172(9), 862-869.

Rosenthal, N. E., Genhart, M., Sack, D. A., Skwerer, R. G. ve Wehr, T. A. (1987). Seasonal affective disorder: Relevance for treatment and research of bulimia. Hudson, E. L. ve Pope, H. G. (Eds.), Psychobiology 
of bulimia içinde (205-228). Washington, D.C.: American Psychiatric Press.

Rosenthal, N. E., Sack, D. A., Gillin, J. C., Goodwin, F. K., Davenport, Y., Mueller, P.S., Newsome, D. A. ve Wehr, T. A. (1984). Seasonal affective disorder: A description of the syndrome and preliminary findings with light therapy. Archives of General Psychiatry, 41(1), 72-80.

Ryan, R. M. ve Deci, E. L. (2001). On happiness and human potentials: A review of research on hedonic and eudaimonic well-being. Annual Review of Psychology, 52(1), 141-166.

Schulz, P. ve Steimer, T. (2009). Neurobiology of circadian systems. CNS drugs, 23(2), 3-13.

Selvi, Y., Beșiroğlu, L. ve Aydın, A. (2011). Kronobiyoloji ve duygudurum bozuklukları. Psikiyatride Güncel Yaklaşımlar, 3(3), 368-386.

Serin, N. B., Serin, O. ve Özbaş, L. F. (2010). Predicting university students' life satisfaction by their anxiety and depression level. Procedia Social and Behavioral Sciences, 9, 579-582.

Simrén, M., Axelsson, J., Gillberg, R., Abrahamsson, H., Svedlund, J. ve Björnsson, E. S. (2002). Quality of life in inflammatory bowel disease in remission: The impact of IBS like symptoms and associated psychological factors. The American Journal of Gastroenterology, 97(2), 389-396.

Şahin, N. H. ve Durak, A. (1994). Kısa semptom envanteri: Türk gençleri için uyarlanması. Türk Psikoloji Dergisi, 9(31), 44-56.

Taylor, S. E., Peplau, L. A. ve Sears, D. O. (2010). Sosyal psikoloji. (A. Dönmez, Çev.). Ankara: İmge Kitabevi. (Orijinal çalışma basım tarihi 2008)

Terman, M. ve Terman, J. S. (2005). Light therapy. Principles and Practice of Sleep Medicine, 4, 1424-1442.

Tuzgöl-Dost, M. (2004). Üniversite öğrencilerinin öznel iyi oluş düzeyleri. Yayınlanmamış doktora tezi, Hacettepe Üniversitesi Sosyal Bilimler Enstitüsü.

Tülek, N. (2011). Evli bireylerin öznel iyi olma düzeylerinin yordanmast. Yayınlanmamış yüksek lisans tezi, Ege Üniversitesi Sosyal Bilimler Enstitüsü.

Tümkaya, S. (2011). Türk üniversite öğrencilerinde öznel iyi oluşu yordayan sosyodemografik değişkenler ve mizah tarzları. Eğitim ve Bilim Dergisi, 36(160), 158-170. 
Winthorst, W. H., Roest, A. M., Bos, E. H., Meesters, Y., Penninx, B. W., Nolen, W. A. ve Jonge, P. (2014). Self attributed seasonality of mood and behavior: A report from the Netherlands study of depression and anxiety. Depression and Anxiety, 31(6), 517-523.

Wirz-Justice, A. (2006). Biological rhythm disturbances in mood disorders. International Clinical Psychopharmacology, 21, 11-15.

Wirz-Justice, A. (2008). Diurnal variation of depressive symptoms. Dialogues in Clinical Neuroscience, 10(3), 337-343.

Yöney, T. H., Taybili, B. ve Göktepe, E. O. (1995). İstanbul'da üniversite ögrencilerinde mevsimsellik üzerine bir çalışma. Düşünen Adam, l, $38-42$. 